Article

\title{
Application of Plasmid Engineering to Enhance Yield and Quality of Plasmid for Vaccine and Gene Therapy
}

\author{
Olusegun Folarin ${ }^{\circledR}$, Darren Nesbeth ${ }^{\circledR}$, John M. Ward and Eli Keshavarz-Moore * \\ Advanced Center for Biochemical Engineering, University College London, London WC1E 6BT, UK; \\ olusegun.folarin.14@ucl.ac.uk (O.F.); d.nesbeth@ucl.ac.uk (D.N.); j.ward@ucl.ac.uk (J.M.W.) \\ * Correspondence: e.keshavarz-moore@ucl.ac.uk; Tel.: +44-020-7679-2961
}

Received: 22 May 2019; Accepted: 14 June 2019; Published: 19 June 2019

\begin{abstract}
There is an increased interest in plasmid DNA as therapeutics. This is evident in the number of ongoing clinical trials involving the use of plasmid DNA. In order to be an effective therapeutic, high yield and high level of supercoiling are required. From the bioprocessing point of view, the supercoiling level potentially has an impact on the ease of downstream processing. We approached meeting these requirements through plasmid engineering. A $7.2 \mathrm{~kb}$ plasmid was developed by the insertion of a bacteriophage $\mathrm{Mu}$ strong gyrase-binding sequence (Mu-SGS) to a $6.8 \mathrm{~kb}$ pSV $\beta$-Gal and it was used to transform four different $E$. coli strains, and cultured in order to investigate the Mu-SGS effect and dependence on strain. There was an increase of over $20 \%$ in the total plasmid yield with pSV $\beta-G a l 398$ in two of the strains. The supercoiled topoisomer content was increased by $5 \%$ in both strains leading to a $27 \%$ increase in the overall yield. The extent of supercoiling was examined using superhelical density $(\sigma)$ quantification with $\mathrm{pSV} \beta$-Gal398 maintaining a superhelical density of -0.022 , and PSV $\beta$-Gal -0.019 , in both strains. This study has shown that plasmid modification with the Mu-phage SGS sequence has a beneficial effect on improving not only the yield of total plasmid but also the supercoiled topoisomer content of therapeutic plasmid DNA during bioprocessing.
\end{abstract}

Keywords: E. coli; plasmid bioprocessing; plasmid supercoiling; superhelical density; plasmid engineering; nanoparticle tracking analysis (NTA)

\section{Introduction}

The past few decades have seen a rise in the focus of plasmid DNA for biotherapeutic production, with applications including vaccines and gene therapy. The reasons include, but not exhaustively, the ability to elicit both humoral and cell-mediated immune response [1-3] as well as the possibility of having multiple protection from one preparation. The rise in the application of plasmid DNA for vaccine and gene therapy is evident in ongoing clinical trials, with about $17.4 \%$ of all gene therapy clinical trials involving plasmid DNA [4]. Although there are presently no approved DNA vaccines for use in humans, there has been tremendous progress in the development of these vaccines, particularly DNA vaccines targeting HPV-derived onco-antigens [5], and a number of completed clinical trials on DNA vaccines for oncological indications which are extensively discussed in [6,7]. It is therefore no surprise that this particular class of biomolecule is receiving such great attention.

An ample amount of plasmid DNA (pDNA) is required (in $\mathrm{mg}$ ) because not all of it is integrated during transfection and it must be mostly in the supercoiled form (in comparison to a linear and nicked form) to be effective for biotherapeutic applications [8]. Therefore, two bioprocess challenges that need to be addressed are the yield and the quality (i.e., maintaining a high supercoiled fraction) of the plasmid DNA. Increasing the plasmid yield has been well studied, but there is minimal information about increasing the supercoiling of the plasmid. A study carried out by Adamcik et al. highlighted how temperature affects the distribution of topoisomers in plasmid preparation and the impact on 
supercoiling of the preparation [9]. For instance, it has been reported that by achieving a high cell density culture, the plasmid yield is improved as plasmid production is directly linked to the biomass yield of a culture [10]. Some of these reports have achieved high biomass yield by engineering the cell using gene knockout or gene overexpression. Examples include the knockout of the pts gene responsible for glucose transport and replacement with galp + which codes for permease [11,12], modification of pentose phosphate pathway [13], and knocking out the pyruvate kinase gene [14].

In addition, attempts have been made to modify culture media to achieve high plasmid yield. O'Kennedy et al. [15] reported that at a specific ratio of carbon to nitrogen, the plasmid yield is increased. Supplementation of optimized concentrations of glutamate and ammonium chloride have also been reported to improve plasmid DNA production [16]. It has also been reported that a semi-defined medium supplemented with casamino acid (SDCAS) supported high yield and plasmid stability as compared with a medium containing soy amino acids and LB medium [15]. All of these reports have tackled the plasmid yield, however, maintaining a high supercoiling is still a challenge that needs addressing.

In addition to a high supercoiled amount being required for the effectiveness of plasmid use for vaccine and gene therapy applications, it makes plasmid more compact as the plasmid becomes coiled due to the twisting and writhing associated with supercoiling. This is potentially essential for downstream processing of plasmid as these molecules are sensitive to shear during downstream processes such as centrifugation, flow through pumps $[17,18]$, and filtration. The sensitivity of plasmid DNA to shear is also dependent on the size of the plasmid, hence by making plasmid more compact we reduce the sensitivity on exposure to shear.

Several studies have investigated external factors and their effects on plasmid supercoiling [19-21]. However, there are very few reports that have investigated the effect of plasmid DNA modification aimed at increasing supercoiling and superhelical density (measurement of the compactness of the DNA) of the plasmid DNA [22]. The DNA negative supercoiling is introduced by the DNA gyrase, a Type II topoisomerase that is tightly regulated alongside the DNA topoisomerase I, which relaxes the DNA [23]. DNA gyrase overexpression in E. coli has only led to a slight increase in plasmid supercoiling [24].

The catalytic activity of the DNA gyrase involves binding to a specific sequence on the DNA and using energy from ATP to introduce a negative supercoil into the DNA [25]. Identifying the sequence and exploiting the extent binding increases the rate at which gyrase introduces supercoils into the DNA. A number of strong gyrase binding sites have been identified in plasmid pBR322, pSC101, and the bacteriophage $\mathrm{Mu}$. The Mu-phage gyrase binding sequence has been reported to have a strong affinity for the binding of gyrase, hence stimulating the replication and packaging of the Mu bacteriophage in its host [26]. This sequence is found in the middle of the $37 \mathrm{~kb}$ genome of the bacteriophage $\mathrm{Mu}$ and contains an 8 bp sequence where the gyrase binds and inserts supercoil into the Mu genome [27].

Exploiting the efficiency of the Mu-phage SGS for increasing DNA supercoil and superhelical density means increasing the supercoil nature of the plasmid further. Further studies have shown that the length of the left and right of the key sequence on Mu-phage SGS also affects the efficiency of the sequence to insert a supercoil into the plasmid DNA. In a separate study, Hassan et al. [22] tested different lengths of the SGS and found that the $398 \mathrm{bp}$ sequence, which is the longest of the different SGS lengths tested, significantly increased the plasmid supercoiling and superhelical density of a 2.7 $\mathrm{kb}$ plasmid.

Several strains of $E$. coli have been selected for the production of plasmid DNA based on laboratory use and commercial availability. These include E. coli K-12 strains such as JM108 [28], DH5 $\alpha$ [11,15,29], GALG20 [11], BL21(DE3) [30], SCS1-L [31], and DH10B [32]. Usually, host cells are selected based on experiments carried out on the various strains available. Yau et al. [19] demonstrated that there is no direct correlation between the strain and the plasmid, and therefore testing on different strains should be carried out when selecting a strain for specific plasmids. 
In this study, we investigate the impact of the bacteriophage Mu strong gyrase binding site sequence engineered into a $6.8 \mathrm{~kb}$ plasmid and amplified in four different $E$. coli strains which have been selected based on past studies, as well as to examine the effect of the potential increase in supercoiling on the integrity of the plasmid during downstream processing.

\section{Materials and Methods}

\subsection{Strains amd Plasmids}

The pSV $\beta$-galactosidase plasmid vector was employed as the parent plasmid. The plasmid contained the gene coding for ampicillin resistance which was used for its selection upon transformation with a suitable host. The plasmid also contained the SV40 early promoter and enhancer sequence that drove the transcription of a specific lacZ gene on the plasmid. The plasmid was purchased from Promega Corporation (Southampton, UK). The Mu-phage SGS (strong gyrase-binding site) sequence used in this project was as reported by Hassan et al. [22]. The $398 \mathrm{bp}$ sequence was selected from among the three sizes that were reported in the study. The selection of the sequence as a strong binding site for the DNA gyrase in E. coli was based on the report by Pato and Banerjee [26]. The Mu-phage SGS sequence was taken from the European Nucleotide Archive of the European Bioinformatics Institute (EBI). The sequence was found on position $17,681 \mathrm{bp}-18,078 \mathrm{bp}$ of the $37 \mathrm{~kb}$ bacteriophage Mu genome. The sequence was prepared as a synthetic gene and cloned into the plasmid vector by Genscript Corporation (Genscript, Picastaway, NJ, USA). The resulting plasmid vector was named pSV $\beta$-gal398.

The E. coli strains selected for this study were based on the studies of Yau et al. [19]. The strains were also selected based on their industrial relevance and commercial availability. Several strains were derivatives of the parent E. coli strain K-12. Table 1 shows the summary of the genotype of these strains. All of the strains that were acquired in-house or commercially purchased, were then transformed with plasmids pSV $\beta$-Gal and pSV $\beta$-Gal398 using a standard heat shock calcium chloride technique [33]. The cells were prepared as glycerol stocks and were transferred into cryovials and stored at $-80^{\circ} \mathrm{C}$ until required.

Table 1. Strains selected for the study and their genotype.

\begin{tabular}{|c|c|c|c|}
\hline Strain & Genotype & Source & Status \\
\hline BL-21 & $\begin{array}{c}F^{-} d c m h s d S\left(r_{B}^{-} m_{B}^{-}\right) \operatorname{gal} \Delta(D E 3) \\
F^{-} \text {end } A 1 \text { glnV44 thi- }\end{array}$ & [34] & Commercial \\
\hline DH5 $\alpha$ & $\begin{array}{c}1 \text { recA1 relA1 gyrA96 deoR nup } G 80 \text { dlacZ } \Delta M 15 \Delta(\operatorname{lacZYA-} \\
\operatorname{argF}) U 169, \text { hsdR17 }\left(r_{K}^{-} m_{K}^{+}\right), \lambda^{-}\end{array}$ & {$[35,36]$} & Commercial \\
\hline HB101 & $\begin{array}{c}F-m c r B \text { mrr } h s d S 20(r B-m B-) r e c A 13 l e u B 6 a r a \\
-14 \text { proA2 lac } Y 1 \text { galK2 } x y l-5 m t l \\
-1 \text { rpsL20 }(S m R) g \ln V 44 \lambda-\end{array}$ & [37] & Non-commercial \\
\hline W3110 & $F-\lambda-r p h-1 \operatorname{INV}(r r n D, r r n E)$ & [38] & Non-commercial \\
\hline
\end{tabular}

The transformed cells, stored in glycerol, were thawed and used to streak LB agar (yeast extract, $5.0 \mathrm{~g} / \mathrm{L}$, tryptone $10.0 \mathrm{~g} / \mathrm{L}$, sodium chloride $5.0 \mathrm{~g} / \mathrm{L}$, and agar $15 \mathrm{~g} / \mathrm{L}$ ) plates which contained ampicillin for the selection and growth of plasmid containing cells. The ampicillin concentration used was $100 \mu \mathrm{g} / \mathrm{mL}$. The plates were then incubated at $37^{\circ} \mathrm{C}$ for $24 \mathrm{~h}$, wrapped in film, and stored at $4{ }^{\circ} \mathrm{C}$ until they were required.

\subsection{Fermentation}

Two cultures ( $5 \mathrm{~mL}$ and $10 \mathrm{~mL}$ ) containing LB media and the appropriate antibiotics (ampicillin) were grown in $50 \mathrm{~mL}$ falcon tubes for $16 \mathrm{~h}$ at $37^{\circ} \mathrm{C}$ in an incubator with an agitation speed of $250 \mathrm{rpm}$. The media were inoculated with single picked colonies from freshly prepared agar plates. For shake flask fermentation, the inoculum was prepared by inoculating $10 \mathrm{~mL}$ of culture from glycerol stock 
and incubating it in a shaker at $37^{\circ} \mathrm{C}$ overnight. The overnight culture was used to inoculate $200 \mathrm{~mL}$ of LB media containing ampicillin in a $1 \mathrm{~L}$ shake flask and placed in an orbital shaker at $37^{\circ} \mathrm{C}$ with an agitation speed of $250 \mathrm{rpm}$. For the $5 \mathrm{~mL}$ culture, samples were taken from the culture at the end of the fermentation and the optical density $\left(\mathrm{OD}_{600 \mathrm{~nm}}\right)$ was measured with a spectrophotometer at a wavelength of $600 \mathrm{~nm}$. The OD was used to predict the biomass yield per $\mathrm{mL}$ of culture.

For the shake flask culture, samples were taken from the culture hourly and the optical density was measured using a spectrophotometer with a wavelength of $600 \mathrm{~nm}$. The OD was used to predict the biomass yield per $\mathrm{mL}$ of culture. The optical density obtained was used to plot the growth curve of the fermentation.

\subsection{Plasmid Extraction and Purification}

Plasmid DNA samples from the fermentation was extracted and purified using the Qiagen Spin Mini Prep kits and the Qiagen Maxi prep kits (Qiagen Ltd, Sussex, UK). The procedure was followed according to the protocols provided with the kits by the manufacturer. The plasmid yield was determined by measuring the concentration of the plasmid DNA in the purified samples. The concentration was determined by spectrophotometry using the Nanodrop ND-1000 Spectrophotometer (Nanodrop, Willington, DE, USA).

\subsection{Determination of Plasmid Topology}

To determine the different topoisomers (linearized, open-circular, and supercoiled) of the plasmid DNA present in the samples, linearized and open circular (also known as nicked) plasmid samples were prepared and run alongside the samples during agarose gel electrophoresis. To prepare open-circular plasmid, $2 \mu \mathrm{L}$ of the enzyme Nt.Bst.NBI (NEB, UK) was added to a preparation of $2 \mu \mathrm{L}$ plasmid DNA, $5 \mu \mathrm{L}$ of $10 \mathrm{X}$ buffer, and $41 \mu \mathrm{L}$ of water. The mixture was incubated at $55^{\circ} \mathrm{C}$ for $1 \mathrm{~h}$ followed by inactivation of the enzyme at $80^{\circ} \mathrm{C}$ for $20 \mathrm{~min}$. To prepare the linear plasmid, $2 \mu \mathrm{L}$ of the enzyme BamHI (NEB, UK) was added to the preparation of $2 \mu \mathrm{L}$ plasmid DNA (equivalent to $1 \mu \mathrm{g}$ ), $5 \mu \mathrm{L}$ of 10X Cutsmart buffer, and $41 \mu \mathrm{L}$ of water. The mixture was incubated at $37^{\circ} \mathrm{C}$ for $15 \mathrm{~min}$.

The plasmid DNA topology compositions and percentage intensities were determined using agarose gel electrophoresis and $0.8 \%(w / v)$ agarose gel was prepared in $1 \mathrm{X}$ TAE (tris-acetate-EDTA) buffer (Sigma-Aldrich, St. Louis, MI, USA). The gel was prestained with ethidium bromide $(500 \mu \mathrm{g} / \mathrm{mL}$ ) and run in 1X TAE (tris-acetate-EDTA) buffer at $90 \mathrm{~V}$ for $2 \mathrm{~h}$. The gel was viewed under a UV light and the image was acquired using the AlphaImager Mini System (ProteinSimple, San Jose, CA, USA). A subsequent method involved the use of SYBR ${ }^{\circledR}$ Gold which was used to stain the gel after electrophoresis. The stained gel was viewed under blue fluorescence using the Amersham Imager 600 (GE Healthcare). The AlphaView CA Software (ProteinSimple, Version 3.4.0.0, San Jose, CA, USA) was used to identify the bands and as a densitometry tool to quantify the intensity of the bands on the acquired image of the gel.

\subsection{Determination of Plasmid Superhelical Density}

The plasmid super-helical density was determined using chloroquine agarose gel electrophoresis with a slight modification of the method reported by Bowater [39]. Agarose $(0.7 \% w / v)$ was prepared in $1 \times$ TBE (tris-borate-EDTA) buffer (Sigma Aldrich). Before running, $1.2 \mathrm{mg} / \mathrm{L}$ of chloroquine diphosphate was used to prestain the gel. The sample was loaded, and electrophoresis was carried out in the first dimension at $2 \mathrm{~V} / \mathrm{cm}$ for $20 \mathrm{~h}$ with $1 \times \mathrm{TBE}$ containing the same concentration of chloroquine diphosphate as the running buffer. The electrophoresis was stopped, and the gel was allowed to soak in $1 \times \mathrm{TBE}$ buffer with $6 \mathrm{mg} / \mathrm{L}$ chloroquine diphosphate for $3 \mathrm{~h}$. Electrophoresis was carried out in the second dimension, $90^{\circ}$ to the first at $1.8 \mathrm{~V} / \mathrm{cm}$ for $24 \mathrm{~h}$ with $1 \times \mathrm{TBE}$ containing the same concentration of chloroquine diphosphate in the soaking buffer as the running buffer. Gel was then rinsed three 
times in water for an hour each. The gel was stained with SYBR gold nucleic acid stain for $1 \mathrm{~h}$ before visualization under a UV light. The superhelical density was calculated as follows:

$$
\begin{gathered}
\sigma=\frac{\Delta L k}{L k_{o}} \\
L k_{o}=\frac{N_{o}}{h_{o}}
\end{gathered}
$$

where, $\Delta L k$ is the linking difference determined from the gel image as the number of bands, $L k_{o}$ is the linking number determined from the size of the plasmid in $b p, N$, and number of base pairs per each helical turn assumed to be $10.5 \mathrm{bp}$.

\subsection{Plasmid Shear Exposure Experiment}

To carry out the shear experiments, the plasmids were diluted in TE buffer to a concentration of $15-20 \mu \mathrm{g} / \mathrm{mL}$. The ultra-scale down (USD) shear device was set to the maximum shear rate of $18,000 \mathrm{rpm}$ (equivalent to $10^{6} \mathrm{~s}^{-1}$ ). Then, $20 \mathrm{~mL}$ of the sample was injected into the USD shear device while avoiding bubbles. With the exception of the controls, the sample was exposed to shear for $20 \mathrm{~s}$, as exposing the sample beyond this time had no effect on the plasmids [40]. After exposure to shear, samples were collected and run on agarose gel electrophoresis to determine the percentage of supercoil content. The supercoiled content was expressed as a fraction of the supercoiled content of the control.

\subsection{Plasmid Hydrodynamic Diameter}

The plasmid hydrodynamic diameter $\left(D_{h}\right)$ was determined using the nanoparticle tracking analysis (NTA). This was done using the Nanosight NS300 (Malvern Instrument, UK). Using an inlet syringe pump, $1 \mathrm{~mL}$ of sample prepared in filtered TE buffer was injected into the sample chamber. The laser module was then mounted, and the camera started. Once the recording was complete, standard measurement tracking analysis was carried out in triplicate and the average recorded on the NTA software. The output showed the distribution of particles in the sample with mean size and modal size recorded. A detailed protocol is reported in [41].

\section{Results}

\subsection{Effects of SGS on Plasmid Yield and Supercoiling and Strain Selection}

Figure 1 shows the results observed for the four different strains selected with respect to the plasmid yield and supercoil topoisomer content of the extracted plasmid. A similar fermentation approach was implemented on the four strains as detailed in the materials and methods. Results are the average of the triplicates for each strain-plasmid combination. The biomass yield is reported as OD600nm. All results were subjected to statistical analysis to test for significantly different observations. A significantly higher plasmid yield was observed for SGS-containing plasmid pSV $\beta$-gal398 as compared with the parent plasmid pSV $\beta$-gal. The increase plasmid yield for pSV $\beta$-gal398 was observed in the strains DH5 $\alpha$ and HB101 with an increase of $36 \%$ and $27 \%$, respectively, as compared with pSV $\beta$-gal $(p<0.05$ when subjected to a t-test between the two plasmids in each strain, however this was not the case for the other two strains W3110 and BL21(DE3). 


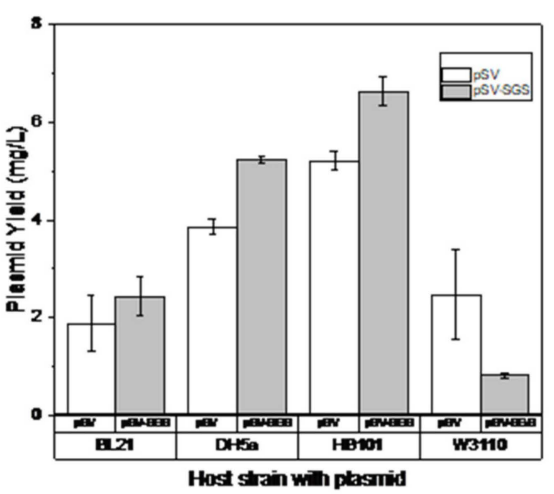

(a)

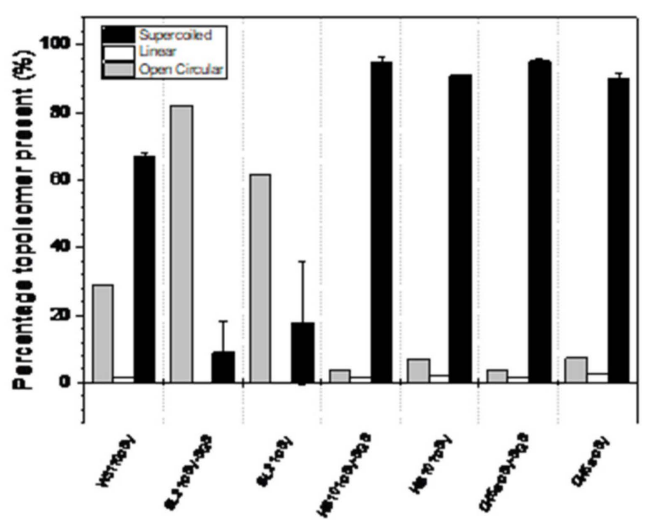

(b)

Figure 1. Plasmid yield and supercoiling of pSV $\beta$-gal398 (pSV-SGS) and pSV $\beta$-gal (pSV) amplified in the four strains. All analyses were done in triplicates. (a) The total plasmid yield (mg/L) of pSV $\beta$-gal398 and pSV $\beta$-gal amplified in the four strains and (b) percentage supercoiled topoisomer content of plasmid extracted from the four strains used. The differences observed were tested statistically with $p<0.05$.

The supercoiled content was determined according to the method describe in the materials and method section. The supercoil percentage shown in the figure is expressed as mean of triplicates \pm SEM the differences observed was subjected to a paired t-test with a confidence limit of $95 \%$. Similar to the plasmid yield discussed above, a high supercoiled content was observed in DH5 $\alpha$ and HB101 with supercoiled content for both SGS-containing plasmid and non-SGS plasmid exceeding $90 \%$ as shown in Figure 1B. However, there was a statistically significant increase (5\%) in the supercoiled content for pSV $\beta$-gal398 as compared with the parent plasmid pSV $\beta$-gal ( $p$-value $<0.05$ in both strains).

Figure 2A shows results of the shake flask fermentation growth curve for E. coli strains DH5 $\alpha$ and HB101 harboring pSV $\beta$-gal398 and pSV $\beta$-gal. Fermentations were run in triplicates. Figure 2B shows a plot of plasmid yield for E. coli strains $\mathrm{DH} 5 \alpha$ and HB101 harboring pSV $\beta$-gal398 and pSV $\beta$-gal. The differences observed between the two plasmids for each strain are statistically significant as it was subjected to a t-test with a confidence limit of $95 \%(p<0.05)$. The plasmid yield differences observed between the two strains were not statistically significant when subjected to a statistical test $(p>0.05)$.

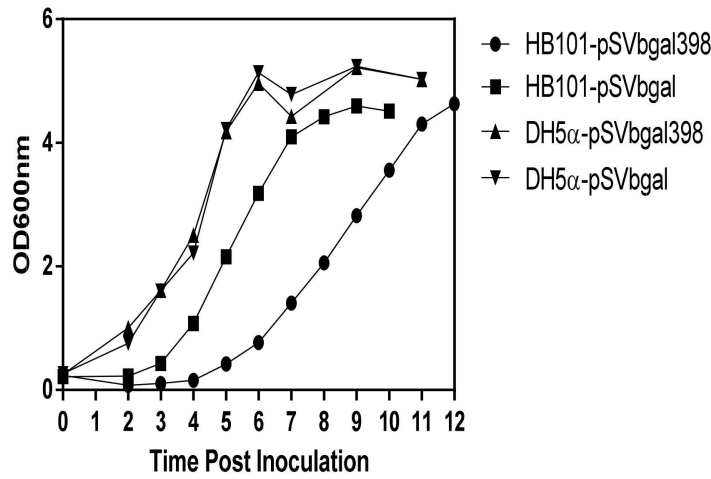

(a)

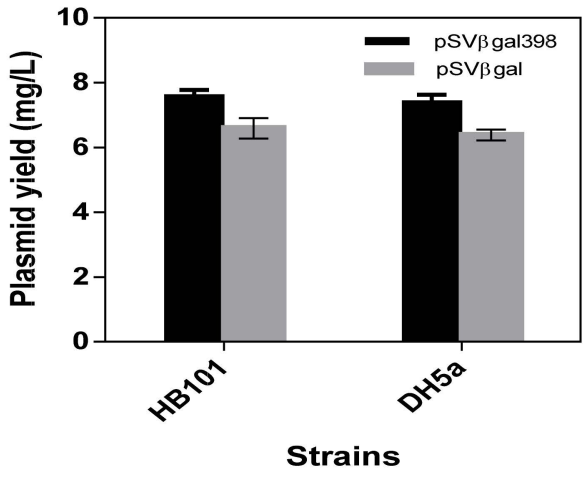

(b)

Figure 2. Characteristics of shake flask fermentation of the two strains HB101 and DH5 $\alpha$. Charts show (a) growth curve of the strains bearing both the non-SGS plasmid and SGS containing plasmid and (b) plasmid yield of pSV $\beta$-gal398 and pSV $\beta$-gal amplified in the two strains. Results are the mean of triplicate samples $(n=3)$. 


\subsection{Effect of SGS Presence on the Superhelical Density of the Plasmid}

Figure 3 a shows a DH5 $\alpha$ sample two-dimensional and one-dimensional chloroquine agarose gel which was run to determine the linking difference of the plasmid. Each sample was run on a single gel, hence it is impossible to show all sample gels. Each band represents the different level of supercoil that is found on the plasmid. The linking difference with the linking number was used to calculate the superhelical density of the plasmid according to the equations in materials and methods. The result for triplicate samples was taken. Figure $3 \mathrm{~B}$ shows the result of the comparison of the superhelical density of the two plasmids (pSV $\beta$-gal398 and pSV $\beta$-gal) amplified in the two strains HB101 and DH5 $\alpha$ expressed as mean \pm SEM. As shown in the graph, the superhelical density of pSV $\beta$-gal398 was approximately -0.022 in both strains as compared with -0.019 for $\mathrm{pSV} \beta$-gal (with $p<0.05$ ).

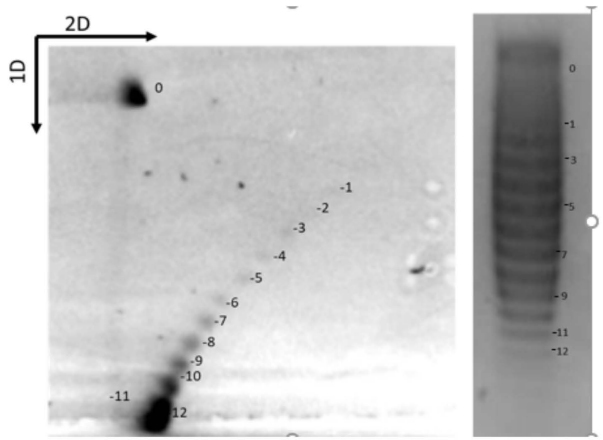

(a)

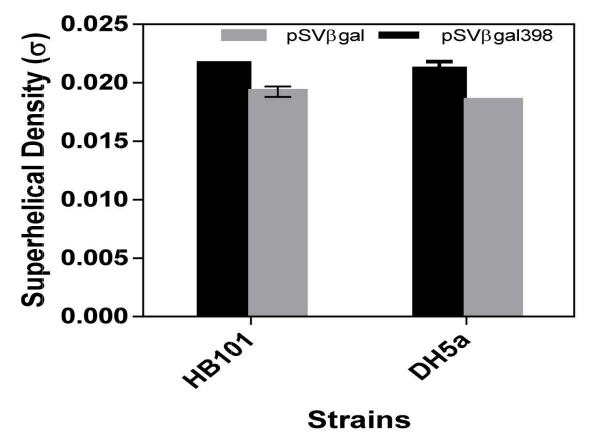

(b)

Figure 3. Superhelical density determination of plasmid amplified in DH5 $\alpha$ and HB101. (a) 2D and 1D chloroquine-agarose gel electrophoresis showing the distribution of topoisomers of the plasmid. The bands depict the linking difference which is then used to calculate the superhelical density (b) Chart showing the superhelical density of pSV $\beta$-gal398 and pSV $\beta$-gal amplified in the two strains. $\mathrm{N}=4$. The difference observed is statistically significant in the two strains $(p<0.05)$.

\subsection{Impact of Increase Supercoiling on Plasmid Integrity}

The plasmid integrity was determined by measuring the supercoiled content of plasmid preparation when exposed to shear. Details of the experiment are in the materials and method section. The shear stress is expressed as the energy dissipation rate and the supercoiled fraction was determined. Figure 4 shows the plot of supercoiled fractions for the two plasmids in each strain. The supercoiled fraction was determined by comparing the supercoiled content of the sheared plasmid relative to the control (non-sheared sample) and expressed as a percentage of the control. Supercoiled fractions are reported as mean \pm SEM. Despite both plasmids maintaining a supercoiled fraction above $90 \%$, there was a higher supercoiled fraction in the plasmid bearing SGS. The differences observed between the plasmid for each strain are statistically significant with a $p$-value $<0.05$ and a confidence limit of $95 \%$. This observation is not surprising as it has been reported that plasmid $<13 \mathrm{~kb}$ are affected minimally by shearing during downstream processing with significant shear observed for plasmid larger than $13 \mathrm{~kb}[17,18]$. Figure $4 \mathrm{c}$ shows the gel image of the sheared plasmid and quantification carried out by densitometric method. Most of the sheared plasmid end up as nicked topology as labelled in the figure. 


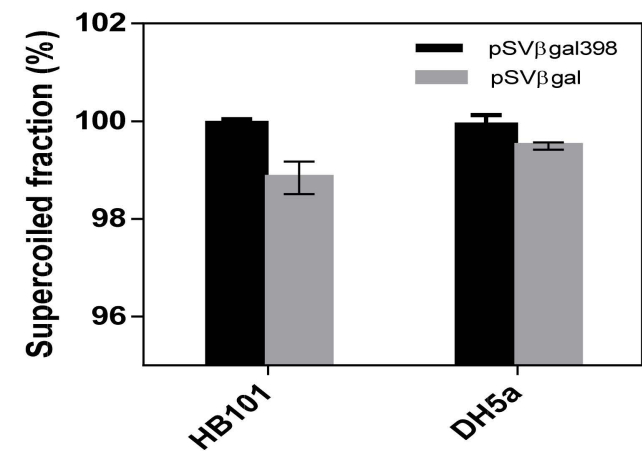

Strains

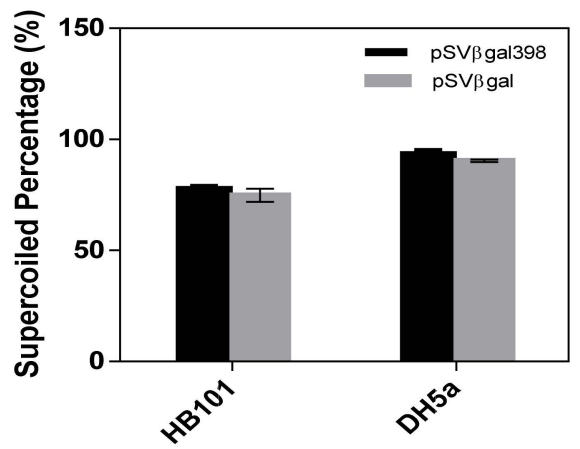

Strains

(a)

(b)

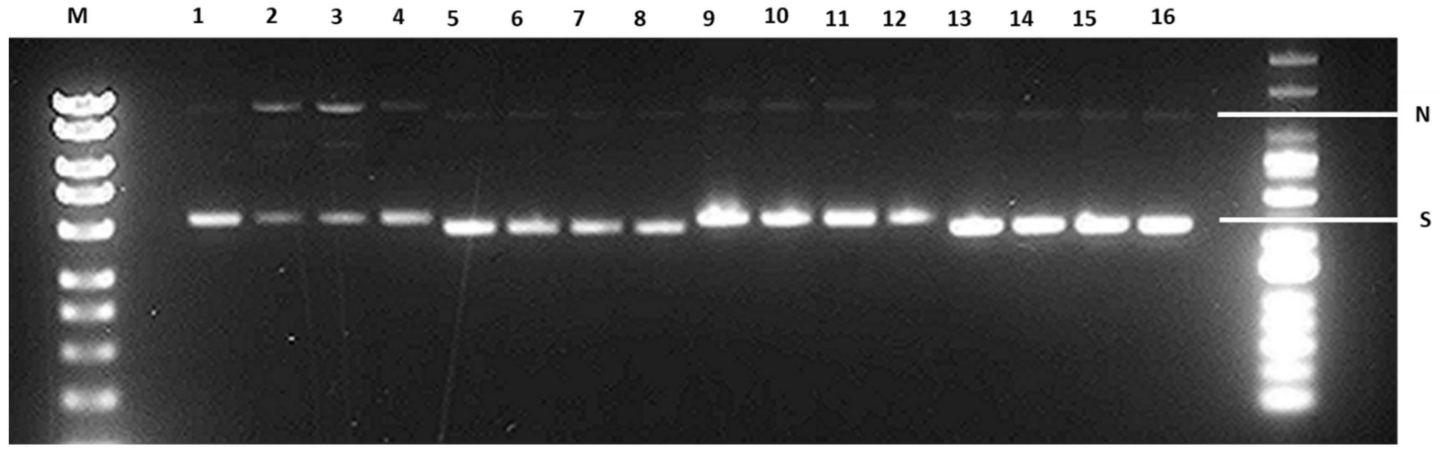

(c)

Figure 4. (a) Supercoiled topoisomer content after exposure to shear using the USD shear device, expressed as a fraction of the control (supercoiled content of non-sheared sample), $n=3$ (b) Supercoiled content of the control sample before shearing. (c) Gel image of the samples after shearing. $\mathrm{M}=$ marker, Lane $1=\mathrm{DH} 5 \alpha / \mathrm{pSV} \beta$-gal398 control sample, Lane $2-4=\mathrm{DH} 5 \alpha / \mathrm{pSV} \beta$-gal398 sheared samples, Lane $5=\mathrm{DH} 5 \alpha / \mathrm{pSV} \beta$-gal control sample, Lane 6-8 = DH5 $\alpha / \mathrm{pSV} \beta$-gal sheared samples, Lane $9=$ HB101/pSV $\beta$-gal398 control sample, Lane 10-12 = HB101/pSV $\beta$-gal398 sheared samples, Lane 13= HB101/pSV $\beta$-gal control sample, Lane 14-16 = HB101/ pSV $\beta$-gal sheared samples, $\mathrm{N}=$ nicked plasmid, and $S=$ supercoiled plasmid.

\subsection{Determination of Plasmid Compactness by Particle Hydrodynamic Diameter Measurement}

Figure 5 shows the results of plasmid hydrodynamic diameter determination using the nanoparticle tracking analysis (NTA) in an attempt to measure the determine plasmid compactness by size measurement. The NTA measures polydisperse particles and Figure $5 c, d$ show the distribution of plasmid in a sample preparation of pSV $\beta$-gal398 and pSV $\beta$-gal amplified in HB101. The peaks are the concentration (particles $/ \mathrm{mL}$ ) of the different isoform of plasmid present in the preparation. The mode of the distribution was used in the analysis as it was expected that most of the plasmid particles were in the supercoiled form. It was confirmed from the densitometry method that the majority of the plasmids were in the supercoiled form. In order to confirm this from the NTA analysis, the hydrodynamic diameter of the nicked and linear plasmid was measured for comparison. Figure 5a shows the hydrodynamic diameter of linearized and nicked pSV $\beta$-gal398. The hydrodynamic diameter is expressed as mean \pm SEM of the triplicate samples. Figure $5 \mathrm{~b}$ shows a plot of the sizes of pSV $\beta$-gal398, pSV $\beta$-gal linear, and nicked plasmid amplified in strains HB101 and DH5 $\alpha$. The results are mean \pm SEM of the triplicate samples. The summary of the hydrodynamic diameter is shown in Table 2 . The result shows that $\mathrm{PSV} \beta$-gal398 is more compact with a lower hydrodynamic diameter as compared with $p S V \beta$-gal in both strains used. 
A

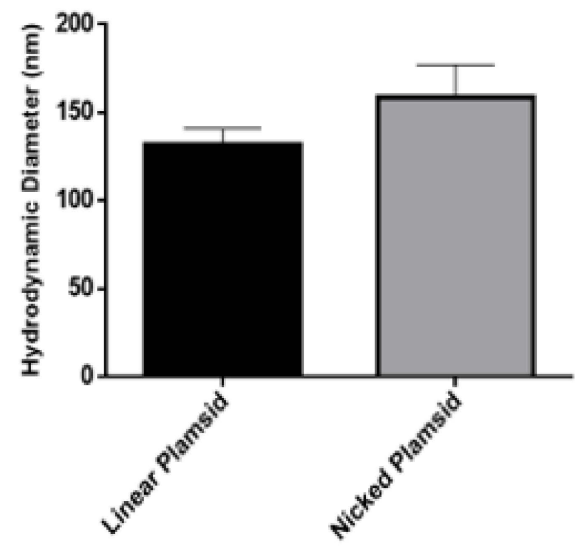

C
B

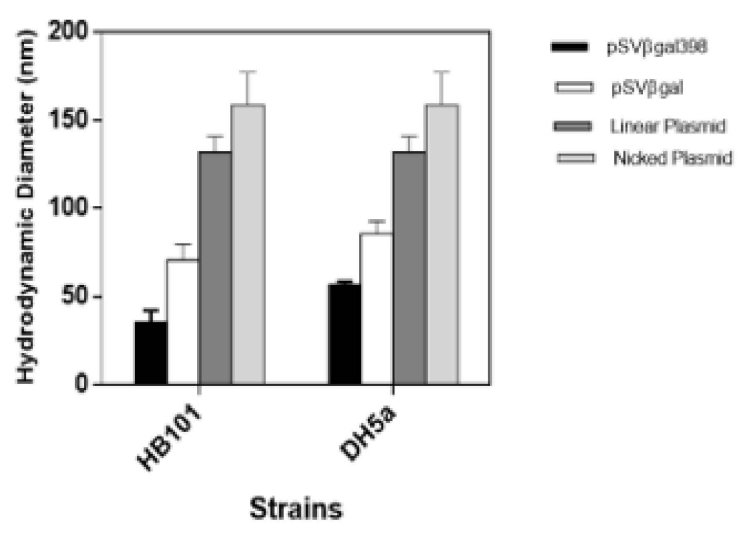

D

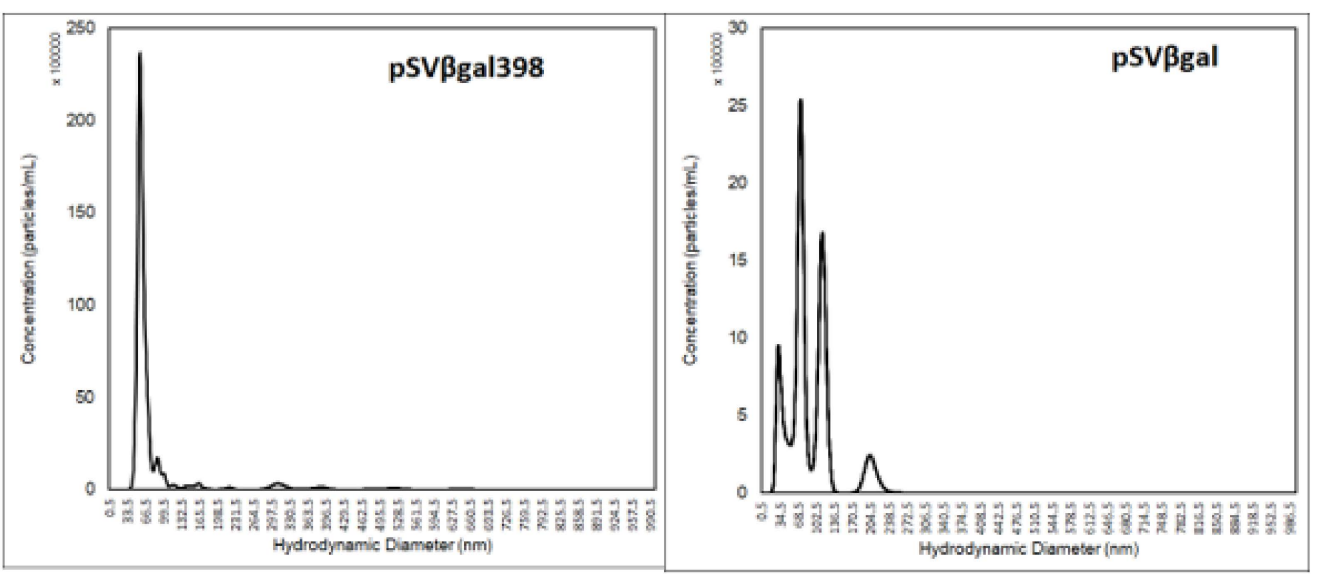

Figure 5. Particle size determination using the nanoparticle tracking analysis which tracks particle based on Brownian motion. Charts showing $(\mathbf{A})$ the hydrodynamic diameter $\left(D_{h}\right)$ of linearized and nicked pSV $\beta$-gal398 plasmid and (B) the hydrodynamic diameter of supercoiled plasmid pSV $\beta$-gal398 and pSV $\beta$-gal in the two strains. The sizes are compared to the nicked and linearized plasmid which are larger than the supercoiled form of the plasmid. (C) and (D) show the particle size distribution of the plasmid pSV $\beta$-gal398 and pSV $\beta$-gal from the strain DH5 $\alpha$. It shows the plot of diameter against concentration in particles $/ \mathrm{mL}$. The analyses were done in triplicate for all samples.

Table 2. Superhelical density and hydrodynamic diameter of the plasmids amplified in different strains. The hydrodynamic diameter is expressed as mean + SEM and $n=3$.

\begin{tabular}{ccccc}
\hline & \multicolumn{2}{c}{ HB101 } & \multicolumn{2}{c}{ DH5 $\alpha$} \\
\cline { 2 - 5 } & $\mathrm{pSV} \beta$-gal398 & $\mathrm{pSV} \beta$-gal & $\mathrm{pSV} \beta$-gal398 & $\mathrm{pSV} \boldsymbol{\beta}$-gal \\
\hline Superhelical density & -0.0218 & -0.0192 & -0.0204 & -0.0185 \\
Hydrodynamic diameter & $39.53 \pm 6.52 \mathrm{~nm}$ & $70.77 \pm 8.84 \mathrm{~nm}$ & $56.97 \pm 1.55 \mathrm{~nm}$ & $85.50 \pm 7.19 \mathrm{~nm}$ \\
Compactness & $44 \%$ more compact & \multicolumn{2}{c}{$34 \%$ more compact } \\
\hline
\end{tabular}

\section{Discussion}

As a result of the progress in some clinical trials involving DNA vaccines, it is expected that these DNA therapeutics will be ready for human use in the next few years [5-7]. This means that a 
cost-effective production platform needs to be ready for mass production. A cost-effective platform would include a high yield and high supercoiled plasmid producing process. Supercoiling is essential for the application of DNA as vaccines and for gene therapy applications. DNA supercoiling is important for processes such as replication, transcription [42], as well as unknotting and decatenation of double stranded DN which are both required for efficient DNA metabolism [43]. Studies have investigated the impact of supercoiling on the efficacy of vaccine with one report suggesting a plasmid preparation containing above $70 \%$ supercoiled topoisomer is capable of inducing immunity compared to the open circular topoisomer and linear topoisomer [8]. In addition, the FDA recommends that plasmid preparation should contain $>80 \%$ supercoiled fraction, and the expectation of the bioprocess industry is that plasmid preparation should contain $>90 \%$ supercoiled content [44]. Hence, it is important to focus on increasing both the yield and the supercoiled topoisomer of plasmid preparation to meet the expected production of therapeutic DNA products.

We have previously identified that a 398 bp Mu-phage SGS induces supercoiling of plasmid DNA [22]. In this study, the $398 \mathrm{bp}$ Mu-phage SGS sequence was introduced into a $7.2 \mathrm{~kb}$ plasmid pSV $\beta$-gal. The study was carried out in small-scale with different strains of E. coli transformed with the SGS and non-SGS containing plasmids. The aim of investigating different strains was to observe the dependency of Mu-SGS on the host strain and to select the best-behaving strain(s). The selected strains were based on the previous report by Yau et al. [19] who reported that plasmid amplification and optimization is host-strain dependent. Therefore, we studied how much impact the host strain would have on the amplification of the recombined plasmid.

There was a high plasmid yield observed in two of the strains used (HB101 and DH5 $\alpha$ ) for plasmid bearing SGS (pSV $\beta$-gal398). The high plasmid yield observed in DH5 $\alpha$ agrees with the review of Lara and Ramirez [10], highlighting DH5 $\alpha$ as a high plasmid yield producing strain specifically designed for plasmid production. HB101 on the other hand has not been extensively employed for plasmid production, most likely due to its high carbohydrate contents which may cause problems during downstream processing [45], however there are a few studies who have reported high plasmid yield using this strain of E. coli $[19,46]$. The significance of the increase in plasmid yield is implicated in the overall plasmid yield which is reported to be around $65 \%$ for a plant designed to produced $141 \mathrm{~g}$ per batch [47].

The supercoiled topoisomer content was also considered for strain-dependence amplification of the SGS-containing plasmid, as this is one of the bioprocess requirement for plasmid DNA production for therapeutic application [48]. Similar to the plasmid yield discussed above, a high supercoiled content was observed in DH5 $\alpha$ and HB101, with supercoiled content for both SGS-containing plasmid and non-SGS plasmid exceeding 90\%, as shown in Figure 1B. However, there was a statistically significant increase $(5 \%)$ in the supercoiled content for pSV $\beta$-gal398 as compared with the parent plasmid pSV $\beta$-gal ( $p$-value $<0.05$ in both strains). This shows the impact of the presence of the Mu-phage SGS sequence which has been reported to increase the supercoiling of DNA due to strong binding of the gyrase [22,49]. The binding of the gyrase to the SGS site induces a nick on the plasmid and enhances supercoiling of the plasmid $[24,50,51]$. The enhancement of supercoiling is shown by the increased superhelical density of the plasmid which is discussed later. A large proportion of the preparation in BL21(DE3) was nicked, as shown in Figure 1B. This shows again that the effect of SGS presence on the supercoiling of the plasmid DNA is strain dependent. A similar result was observed for W3110.

Therefore, on the basis of the result of the initial screening studies on the strains, we selected the two best-behaving strains for further study. The increase in the amount of supercoiled plasmid in the preparation coupled with the increase in plasmid yield further led to an increase in the overall productivity with a $27 \%$ for $\mathrm{pSV} \beta$-gal398 as compared with the unmodified pSV $\beta$-gal.

Figure 2 shows the results of the shake flask fermentation growth curve for E. coli strains DH5 $\alpha$ and HB101 harbouring pSV $\beta$-gal398 and pSV $\beta$-gal. The final biomass yield observed agreed with initial studies with no significant differences between host strain harbouring pSV $\beta$-gal398 and strain 
harbouring pSV $\beta$-gal. We did not expect that there would be a significant difference although the presence of the extra SGS sequence in the PSV $\beta$-gal398 could have added to the metabolic stress on the strain [52], but since it was not expressing any additional recombinant product, the effect would be minimal. However, there was a lower growth rate observed in the strain HB101 but not in DH5 $\alpha$. The presence of the extra sequence on the plasmid may have led to the reduced growth rate observed particularly in HB101 [53]. In addition, the differences in the genotype of both strains may have played a role in the differences observed in the growth curve, for example, DH5 $\alpha$ contained a gyrA96 mutation in the gyrase gene [54]. This mutation may have played a role in the differences observed. The fact that the decrease in growth rate was observed only in HB101 reiterates the reports that bioprocessing of plasmid DNA is strain dependent [19].

The plasmid yield was observed to be higher for pSV $\beta$-gal398 in both the strains $7.63 \mathrm{mg} / \mathrm{L}$ and $7.44 \mathrm{mg} / \mathrm{L}$ in HB101 and DH5 $\alpha$, respectively as compared with the parent plasmid pSV $\beta$-gal with a yield of $6.59 \mathrm{mg} / \mathrm{L}$ and $6.38 \mathrm{mg} / \mathrm{L}$ in $\mathrm{HB} 101$ and $\mathrm{DH} 5 \alpha$, respectively. The increase in plasmid yield was as a result of an increase in plasmid copy number (not shown). The plasmid copy number was investigated as it was clear that the observed increase in plasmid yield was not due to an increase in biomass yield, as the final biomass was similar for the strain-plasmid combinations for the two E. coli strains investigated. The increase in copy number may have been influenced by the presence of SGS on the plasmid, however, this needs further investigation. Another possible reason for the increase in plasmid yield, specifically in HB101, may be the low growth rate, because a low growth rate has been reported to support plasmid amplification [48]. When comparing the two strains carrying the modified plasmid, the differences in the plasmid yield observed may again be as a result of the gyrA96 mutation in DH5 $\alpha$ which is not present in HB101.

Having established the significance of SGS on the yield and supercoiling of plasmid, we set out to determine the extent of supercoiling by determining the superhelical density $(\sigma)$ of the plasmid. This is a measure of how supercoiled a plasmid is in terms of the twist (that is the winding of the DNA helix around its axis) and writhe (the number of times the DNA helix crosses itself) of the two strands on one another [55]. The superhelical density of DNA also measures if the DNA is positively supercoiled or negatively supercoiled. This is determined using the linking number, which quantitatively describes the topology of the plasmid in terms of twist and writhe. With the exception of extreme thermophiles [51], negatively supercoiled DNA is the most preferred topological form of DNA as it facilitates the interaction between replication/transcriptional proteins and DNA [56]. As shown in Figure 3, the superhelical density of pSV $\beta$-gal398 was approximately -0.022 in both strains as compared with -0.019 for $\mathrm{pSV} \beta$-gal $(p<0.05)$. This agrees with earlier report by Hassan et al [22] who observed the same result in a $2.8 \mathrm{~kb}$ plasmid. However, as this was a small-sized plasmid, it was necessary to investigate if this effect was observed for a medium-sized plasmid, as plasmids for therapeutic applications are likely to be in the range of $>6 \mathrm{~kb}$

The increase in superhelicity or superhelical density observed in plasmid carrying the SGS sequence translates to high negative supercoiling. The implication of the high superhelicity to bioprocessing challenges is the possibility of maintaining the integrity of the plasmid during downstream unit operations such as centrifugation and filtration as they would be more compact and less sensitive to shear [17,57]. Moreover, it has been reported that supercoiling is essential for efficient transfection [58]. Therefore, the increase in superhelicity of the plasmid could potentially increase the transfection efficiency of the plasmid [58-60]. The increase in superhelical density is equivalent to an average of two extra linking number differences $(\Delta L k)$ in pSV $\beta$-gal398 compared to $\mathrm{pSV} \beta$-gal. However, both plasmids are negatively supercoiled.

One of the potential benefits of a highly supercoiled plasmid is the maintenance of plasmid integrity during downstream processing due to its high compactness [57]. Plasmid DNA molecules are exposed to elongational shear stress during the centrifugation process as well as in pumps $[17,18]$. Shear stress causes nicking of the plasmid hence reducing the supercoiled plasmid topoisomer content of the final plasmid preparation. We tested how pSV $\beta$-gal398 behaves when exposed to shear since the 
higher superhelical density means it is more compact. The results showed that there was a reduction in the supercoiled content of pSV $\beta$-gal as compared with pSV $\beta$-gal398. The supercoiled content of plasmid pSV $\beta$-gal398 remained intact despite exposing them to shear, although the supercoiled content of the two plasmids preparation was not less than $90 \%$. This observation is not surprising as it has been reported that plasmid with a size of $<13 \mathrm{~kb}$ are affected minimally by shearing during downstream processing with significant shear observed for plasmid larger than $13 \mathrm{~kb}[17,18]$. The maintenance of integrity could be attributed to the increase in compactness of the plasmid [57].

An attempt was made to quantify the compactness of the plasmid by determining the hydrodynamic diameter of the plasmids. Conformational changes induced by SGS presence were determined by measuring the hydrodynamic diameter of the plasmid using nanoparticle tracking analysis (NTA). The NTA measures the hydrodynamic diameter based on the diffusion coefficient of the particle in Brownian motion and then tracks the particle to establish the diameter of the particle. It is able to track single particles with high resolution and detect both high and small particles simultaneously [61]. In addition, NTA is able to measure the concentration of particles in solution [62]. The plasmid hydrodynamic diameter $\left(D_{h}\right)$ was determined using the Nanosight NS300 (Malvern, UK) and both the plasmids pSV $\beta$-gal and pSV $\beta$-gal398 amplified in the strains HB101 and DH5 $\alpha$ were examined.

Figure 5 shows the average hydrodynamic diameter of the linear and nicked plasmid. It is expected that the nicked plasmid will be larger than the linear plasmid as it has been observed during gel electrophoresis that supercoiled plasmid will migrate the fastest due to its tight packing, followed by linear plasmid, with the nicked plasmid migrating the slowest. The supercoiled plasmid is, therefore, expected to have a smaller size relative to linear and nicked plasmid. The hydrodynamic diameter observed also highlighted the compactness of the pSV $\beta$-gal398 as ccompared with pSV $\beta$-gal. For plasmids amplified in the E. coli strain HB101, the modal hydrodynamic diameter for the pSV $\beta$-gal398 is $40 \mathrm{~nm}$ while the modal hydrodynamic diameter of the $\mathrm{pSV} \beta$-gal is $70 \mathrm{~nm}$ (Figure $5 \mathrm{~B}$ ). This supports the observation from the two-dimensional chloroquine agarose gel electrophoresis, where the superhelical density of $\mathrm{pSV} \beta$-gal398 was found to be higher than $\mathrm{pSV} \beta$-gal. The same was observed for plasmids amplified in the E. coli strain DH5 $\alpha$ where the modal hydrodynamic diameter of the pSV $\beta$-gal398 and pSV $\beta$-gal were observed to be $57 \mathrm{~nm}$ and $86 \mathrm{~nm}$, respectively (Figure $5 \mathrm{~B}$ ). This observation agrees with result observed during the measurement of superhelical density where pSV $\beta$-gal398 had a higher superchelical density and hence more compact. The compactness observed is attributed to the presence of the Mu-SGS on the plasmid as reported earlier. This study highlights the possibility of investigating plasmid DNA hydrodynamic size using the nanoparticle tracking analysis (NTA) and to further prove the influence of Mu-SGS presence on the compactness of the plasmid DNA which are requirements for DNA uses for therapeutic applications.

Surprisingly, the effect of Mu-SGS on plasmid supercoiling was observed to be more prominent in plasmids amplified in HB101 in comparison to DH5 $\alpha$, a common E. coli strain for plasmid production. Although, there was an impact of Mu-SGS on the plasmid in both strains, the superhelical density and plasmid hydrodynamic diameter $\left(D_{h}\right)$ show that the plasmids amplified in HB101 are more compact and supercoiled than plasmids amplified in DH5 $\alpha$ (Table 2). The possible explanation goes back to the differences in genotype, and in particular the gyrA96 mutation, as there is a direct interaction between DNA gyrase and the Mu-SGS. This mutation could be limiting the activity of the DNA gyrase on the Mu-SGS due to conformational changes induced by the mutation. This is also evident from the investigation of the effect of shear. As shown in Figure 4, pSV $\beta$-gal398 amplified in HB101 were more resistant to shear effect assuming a 100\% maintenance of integrity after exposure to shear. Yau et al. [19] reported a strain dependency on plasmid production. This study further emphasizes the selection of the right strain for specific plasmid during bioprocessing. 


\section{Conclusions}

The results of this study show that the yield and extent of supercoiling in plasmid is improved by modifying the plasmid, as supercoiling is required for the application of plasmid as biotherapeutics. By increasing the supercoiling, the overall yield of supercoiled plasmid is increased significantly, hence, solving the bioprocess challenge of plasmid yield and quality. We also showed that the effect of SGS is not limited to a $2.8 \mathrm{~kb}$ plasmid as we reported earlier [22]. Increasing the supercoiling also increases the compactness of the plasmid. This is potentially beneficial during downstream processing as an increase in compactness reduces the nicking of plasmid caused by shear exposure.

We also reported that the effect of Mu-SGS to improve the supercoiling of the plasmid DNA is strain dependent, since the effect was more pronounced in strain HB101 as compared with DH5 $\alpha$. Although DH $5 \alpha$ has been widely adopted as a favourite for plasmid production, there is an opportunity for adopting HB101 as a choice of strain. The extent of supercoiling was quantified by measuring the superhelical density of the DNA, a term which employs the linking difference of the plasmid.

To investigate the effect of the Mu-SGS presence on the overall compactness, the hydrodynamic diameter of the plasmid was measured using nanoparticle tracking analysis (NTA). This method was used over the dynamic light scattering (DLS) method because it employs a number-weighted measurement rather than an intensity-weighted average of the DLS. The number-weighted measurement is more reliable as the plasmid preparation is polydispersed. The supercoiled plasmid hydrodynamic diameter was compared to the linearized and nicked plasmids. The results from the NTA also confirmed that the Mu-SGS containing plasmid was more supercoiled compared to the parent plasmid, further strengthening the observations with the superhelical density determination. The study also highlights the possibility of quantifying the extent of plasmid supercoiling using the nanoparticle tracking analysis (NTA).

Author Contributions: Conceptualization, J.M.W. and E.K.-M.; investigation, O.F.; Supervision, D.N., and E.K.-M.; writing —original draft, O.F.; writing—review and editing, O.F., E.K.-M. and J.M.W.

Funding: We are grateful to 1 BRIC grant (BB/E006019/1) from the Biotechnology and Biological Sciences Research Council (BBSRC) Engineering and Physical Sciences Research Council (EPSRC), for funding the initial project and to Federal Scholarship Board (FSB), Nigeria for funding Olusegun Folarin.

Conflicts of Interest: The authors declare no conflict of interest.

\section{References}

1. Brazolot, M.C.L.; Weeratna, R.; Krieg, A.M.; Siegrist, C.A.; Davis, H.L. CpG DNA can induce strong Th1 humoral and cell-mediated immune responses against hepatitis B surface antigen in young mice. Proc. Natl. Acad. Sci. USA 1998, 95, 15553-15558.

2. Okuda, K.; Bukawa, H.; Hamajima, K.; Kawamoto, S.; Sekigawa, K.; Yamada, Y.; Tanaka, S.; Ishi, N.; Aoki, I.; Nakamura, M. Induction of Potent Humoral and Cell-Mediated Immune Responses Following Direct Injection of DNA Encoding the HIV Type 1 env and rev Gene Products. AIDS Res. Hum. Retroviruses. 1995, 11, 933-943. [CrossRef] [PubMed]

3. Chandra, J.; Dutton, J.L.; Li, B.; Woo, W.P.; Xu, Y.; Tolley, L.K.; Yong, M.; Wells, J.W.; Leggatt, S.L.; Finlayson, N.; et al. DNA Vaccine Encoding HPV16 Oncogenes E6 and E7 Induces Potent Cell-mediated and Humoral Immunity Which Protects in Tumor Challenge and Drives E7-expressing Skin Graft Rejection. J. Immunother. 2017, 40, 62-70. [PubMed]

4. Wiley. Gene Therapy Clinical Trials Worldwide [Internet]. J. Gene Med. 2016. Available online: http: //www.wiley.com/legacy/wileychi/genmed/clinical/ (accessed on 13 March 2017).

5. Monie, A.; Tsen, S.W.; Hung, C.F.; Wu, T.C. Therapeutic HPV DNA vaccines. Expert Rev. Vaccines 2009, 8, 1221-1235. [CrossRef] [PubMed]

6. Pierini, S.; Perales-Linares, R.; Uribe-Herranz, M.; Pol, J.G.; Zitvogel, L.; Kroemer, G.; Facciabene, A.; Galluzzi, L. Trial watch: DNA-based vaccines for oncological indications. Oncoimmunology 2017, 6, e1398878. [CrossRef] [PubMed] 
7. Hobernik, D.; Bros, M. DNA Vaccines-How Far From Clinical Use? Int. J. Mol. Sci. 2018, 19, 3605. [CrossRef] [PubMed]

8. Cupillard, L.; Juillard, V.; Latour, S.; Colombet, G.; Cachet, N.; Richard, S.; Blanchard, S.; Fischer, L. Impact of plasmid supercoiling on the efficacy of a rabies DNA vaccine to protect cats. Vaccine 2005, 23, 1910-1916. [CrossRef]

9. Adamčík, J.; Víglasky', V.; Valle, F.; Antalík, M.; Podhradsky', D.; Dietler, G. Effect of bacteria growth temperature on the distribution of supercoiled DNA and its thermal stability. Electrophoresis 2002, 23, 3300-3309. [CrossRef]

10. Lara, A.R.; Ramírez, O.T. Plasmid DNA production for therapeutic applications. Methods Mol. Biol. 2012, 824, 271-303.

11. Gonçalves, G.L.; Prather, K.L.; Monteiro, G.A.; Carnes, A.E.; Prazeres, D.M. Plasmid DNA production with Escherichia coli GALG20, a pgi-gene knockout strain: Fermentation strategies and impact on downstream processing. J. Biotechnol. 2014, 186, 119-127. [CrossRef]

12. Knabben, I.; Regestein, L.; Marquering, F.; Steinbusch, S.; Lara, A.R.; Büchs, J. High cell-density processes in batch mode of a genetically engineered Escherichia coli strain with minimized overflow metabolism using a pressurized bioreactor. J. Biotechnol. 2010, 150, 73-79. [CrossRef]

13. Flores, S.; de Anda-Herrera, R.; Gosset, G.; Bolívar, F.G. Growth-rate recovery of Escherichia coli cultures carrying a multicopy plasmid, by engineering of the pentose-phosphate pathway. Biotechnol. Bioeng. 2004, 87, 485-494. [CrossRef] [PubMed]

14. Cunningham, D.S.; Liu, Z.; Domagalski, N.; Koepsel, R.R.; Ataai, M.M.; Domach, M.M. Pyruvate kinase-deficient Escherichia coli exhibits increased plasmid copy number and cyclic AMP levels. J. Bacteriol. 2009, 191, 3041-3049. [CrossRef]

15. O'Kennedy, R.D.; Baldwin, C.; Keshavarz-Moore, E. Effects of growth medium selection on plasmid DNA production and initial processing steps. J. Biotechnol. 2000, 76, 175-183. [CrossRef]

16. Voss, C.; Schmidt, T.; Schleef, M.; Friehs, K.; Flaschel, E. Effect of ammonium chloride on plasmid DNA production in high cell density batch culture for biopharmaceutical use. J. Chem. Technol. Biotechnol. 2004, 79, 57-62. [CrossRef]

17. Levy, M.S.; Collins, I.J.; Yim, S.S.; Ward, J.M.; Titchener-Hooker, N.; Shamlou, P.A.; Dunnill, P. Effect of shear on plasmid DNA in solution. Bioprocess Eng. 1999, 20, 7. [CrossRef]

18. Zhang, H.; Kong, S.; Booth, A.; Boushaba, R.; Levy, M.S.; Hoare, M. Prediction of Shear Damage of Plasmid DNA in Pump and Centrifuge Operations Using an Ultra Scale-Down Device. Biotechnol. Prog. 2007, 23, 858-865. [CrossRef]

19. Yau, S.Y.; Keshavarz-Moore, E.; Ward, J. Host strain influences on supercoiled plasmid DNA production in Escherichia coli: Implications for efficient design of large-scale processes. Biotechnol. Bioeng. 2008, 101, 529-544. [CrossRef]

20. O'Kennedy, R.D.; Ward, J.M.; Keshavarz-Moore, E. Effects of fermentation strategy on the characteristics of plasmid DNA production. Biotechnol. Appl. Biochem. 2003, 37, 83. [CrossRef]

21. Mizushima, T.; Kataoka, K.; Ogata, Y.; Inoue, R.; Sekimizu, K. Increase in negative supercoiling of plasmid DNA in Escherichia coli exposed to cold shock. Mol. Microbiol. 1997, 23, 381-386. [CrossRef]

22. Hassan, S.; Keshavarz-Moore, E.; Ward, J. A cell engineering strategy to enhance supercoiled plasmid DNA production for gene therapy. Biotechnol Bioeng. 2016, 113, 2064-2071. [CrossRef] [PubMed]

23. Champoux, J.J. DNA Topoisomerases: Structure, Function, and Mechanism. Annu. Rev. Biochem. 2001, 70, 369-413. [CrossRef] [PubMed]

24. Snoep, J.L.; van der Weijden, C.C.; Andersen, H.W.; Westerhoff, H.V.; Jensen, P.R. DNA supercoiling in Escherichia coli is under tight and subtle homeostatic control, involving gene-expression and metabolic regulation of both topoisomerase I and DNA gyrase. Eur. J. Biochem. 2002, 269, 1662-1669. [CrossRef] [PubMed]

25. Reece, R.J.; Maxwell, A.; Wang, J.C. DNA Gyrase: Structure and Function. Crit. Rev. Biochem. Mol. Biol. 1991, 26, 335-375. [CrossRef] [PubMed]

26. Pato, M.L.; Banerjee, M. Replacement of the bacteriophage Mu strong gyrase site and effect on Mu DNA replication. J. Bacteriol. 1999, 181, 5783-5789. [PubMed] 
27. Morgan, G.J.; Hatfull, G.F.; Casjens, S.; Hendrix, R.W. Bacteriophage Mu genome sequence: Analysis and comparison with Mu-like prophages in Haemophilus, Neisseria and Deinococcus. J. Mol. Biol. 2002, 317, 337-359. [CrossRef] [PubMed]

28. Huber, H.; Pacher, C.; Necina, R.; Kollmann, F.R.C. Method for producing plasmid DNA on a manufacturing scale by fermentation of the Escherichia coli K-12 strain JM108. World Patent WO/2005/098002, 21 October 2005.

29. Borja, G.M.; Meza, M.E.; Barrón, B.; Gosset, G.; Ramírez, O.T.; Lara, A.R. Engineering Escherichia coli to increase plasmid DNA production in high cell-density cultivations in batch mode. Microb. Cell Fact. 2012, 11, 132. [CrossRef]

30. Phue, J.N.; Lee, S.J.; Trinh, L.; Shiloach, J. Modified Escherichia coli B (BL21), a superior producer of plasmid DNA compared with Escherichia coli K (DH5alpha). Biotechnol. Bioeng. 2008, 101, 831-836. [CrossRef]

31. Singer, A.; Eiteman, M.; Altman, E. DNA plasmid production in different host strains of Escherichia coli. J. Ind. Microbiol. Biotechnol. 2009, 36, 521-530. [CrossRef]

32. Lahijani, R.; Hulley, G.; Soriano, G.; Horn, N.; Marquet, M. High-yield production of pBR322-derived plasmids intended for human gene therapy by employing a temperature-controllable point mutation. Hum. Gene Ther. 1996, 7, 1971-1980. [CrossRef]

33. Sambrook, J.; Fritsch, E.F.; Maniatis, T. Molecular Cloning: A Laboratory Manual, 2nd ed.; Cold Spring Harbor Laboratory Press: New York, NY, USA.

34. Studier, F.W.; Moffatt, B.A. Use of bacteriophage T7 RNA polymerase to direct selective high-level expression of cloned genes. J. Mol. Biol. 1986, 189, 113-130. [CrossRef]

35. Grant, S.G.; Jessee, J.; Bloom, F.R.; Hanahan, D. Differential plasmid rescue from transgenic mouse DNAs into Escherichia coli methylation-restriction mutants. Proc. Natl. Acad. Sci. USA 1990, 87, 4645-4649. [CrossRef] [PubMed]

36. Hanahan, D. Techniques for Transformation of E. coli. DNA Cloning: A Practical Approach; Glover, D.M., Ed.; IRL: Oxford, UK.

37. Boyer, H.W.; Roulland-Dussoix, D. A complementation analysis of the restriction and modification of DNA in Escherichia coli. J. Mol. Biol. 1969, 41, 459-472. [CrossRef]

38. Hayashi, K.; Morooka, N.; Yamamoto, Y.; Fujita, K.; Isono, K.; Choi, S.; Eiichi, O.; Tomoya, B.; Barry, L.; Hirotada, M.; et al. Highly accurate genome sequences of Escherichia coli K-12 strains MG1655 and W3110. Mol. Syst. Biol. 2006, 2. [CrossRef]

39. Bowater, R.; Aboul-Ela, F.; Lilley, D.M. Two-dimensional gel electrophoresis of circular DNA topoisomers. Methods Enzymol. 1992, 212, 105-120. [PubMed]

40. Rayat, A.C.; Chatel, A.; Hoare, M.; Lye, G.J. Ultra scale-down approaches to enhance the creation of bioprocesses at scale: impacts of process shear stress and early recovery stages. Curr. Opin. Chem Eng. 2016, 14, 150-157. [CrossRef]

41. Hou, J.; Ci, H.; Wang, P.; Wang, C.; Lv, B.; Miao, L.; You, G. Nanoparticle tracking analysis versus dynamic light scattering: Case study on the effect of $\mathrm{Ca}^{2+}$ and alginate on the aggregation of cerium oxide nanoparticles. J. Hazard Mater. 2018, 360, 319-328. [CrossRef]

42. Baranello, L.; Levens, D.; Gupta, A.; Kouzine, F. The importance of being supercoiled: How DNA mechanics regulate dynamic processes. BBA-Gene Regul. Mech. 2012, 1819, 632-638. [CrossRef]

43. Witz, G.; Stasiak, A. DNA supercoiling and its role in DNA decatenation and unknotting. Nucleic Acids Res. 2009, 38, 2119-2133. [CrossRef]

44. Hitchcock, A.G.; Sergeant, J.A.; Rahman, S.F.; Tharia, H.A.; Blom, H. Scale-Up of a Plasmid DNA Purification Process. BioProcess International. 2010, pp. 46-54. Available online: http://www.bioprocessintl.com/ analytical/downstream-development/scale-up-of-a-plasmid-dna-purification-process-307226/ (accessed on 18 June 2019).

45. Carnes, A.E. Fermentation Design for the Manufacture of Therapeutic Plasmid DNA. BioProcess Int. 2005. Available online: https://pdfs.semanticscholar.org/fc3a/044506b95c79b913a3536765a1ae4d9e2307.pdf (accessed on 18 June 2019).

46. Duttweiler, H.M.; Gross, D.S. Bacterial growth medium that significantly increases the yield of recombinant plasmid. Biotechniques 1998, 24, 438-444. [CrossRef]

47. Freitas, S.S.; Santos, J.A.L.; Prazeres, D.M.F.; Heinzle, E.; Biwer, A.P.; Cooney, C.L. Plasmid DNA. In Development of Sustainable Bioprocesses; John Wiley \& Sons: Chichester, UK, 2006; pp. 271-285. 
48. Williams, J.A.; Luke, J.; Langtry, S.; Anderson, S.; Hodgson, C.P.; Carnes, A.E. Generic plasmid DNA production platform incorporating low metabolic burden seed-stock and fed-batch fermentation processes. Biotechnol. Bioeng. 2009, 103, 1129-1143. [CrossRef] [PubMed]

49. Oram, M.; Howells, A.J.; Maxwell, A.; Pato, M.L. A biochemical analysis of the interaction of DNA gyrase with the bacteriophage $\mathrm{Mu}$, pSC101 and pBR322 strong gyrase sites: The role of DNA sequence in modulating gyrase supercoiling and biological activity. Mol. Microbiol. 2003, 50, 333-347. [CrossRef] [PubMed]

50. Pato, M.L.; Banerjee, M. Genetic analysis of the strong gyrase site (SGS) of bacteriophage Mu: localization of determinants required for promoting Mu replication. Mol. Microbiol. 2000, 37, 800-810. [CrossRef] [PubMed]

51. Bettotti, P.; Visone, V.; Lunelli, L.; Perugino, G.; Ciaramella, M.; Valenti, A. Structure and Properties of DNA Molecules Over The Full Range of Biologically Relevant Supercoiling States. Sci. Rep. 2018, 8, 6163. [CrossRef] [PubMed]

52. Diaz, R.J.C.; Hernández, M.E. Plasmid Effects on Escherichia coli Metabolism. Crit. Rev. Biotechnol. 2000, 20, 79-108. [CrossRef]

53. Bolivar, F.; Backman, K. Plasmids of Escherichia coli as cloning vectors. Methods Enzymol. 1979, 64, $245-267$.

54. Langley, K.E.; Villarejo, M.R.; Fowler, A.V.; Zamenhof, P.J.; Zabin, I. Molecular basis of beta-galactosidase alpha-complementation. Proc. Natl. Acad. Sci. USA 1254, 72, 1254-1257. [CrossRef] [PubMed]

55. Higgins, N.P.; Vologodskii, A.V. Topological Behavior of Plasmid DNA. Microbiol. Spectr. 2015, 3. [CrossRef]

56. Koster, D.A.; Crut, A.; Shuman, S.; Bjornsti, M.A.; Dekker, N.H. Cellular Strategies for Regulating DNA Supercoiling: A Single-Molecule Perspective. Cell 2010, 142, 519-530. [CrossRef]

57. Ferreira, G.N.M.; Monteiro, G.A.; Prazeres, D.M.F.; Cabral, J.M.S. Downstream processing of plasmid DNA for gene therapy and DNA vaccine applications. Trends Biotechnol. 2000, 18, 380-388. [CrossRef]

58. Dhanoya, A.; Chain, B.M.; Keshavarz-Moore, E. The impact of DNA topology on polyplex uptake and transfection efficiency in mammalian cells. J. Biotechnol. 2011, 155, 377-386. [CrossRef] [PubMed]

59. Weintraub, H.; Cheng, P.; Conrad, K. Expression of transfected DNA depends on DNA topology. Cell 1986, 46, 115-122. [CrossRef]

60. Dhanoya, A.; Chain, B.M.; Keshavarz-Moore, E. Role of DNA topology in uptake of polyplex molecules by dendritic cells. Vaccine 2012, 30, 1675-1681. [CrossRef] [PubMed]

61. Filipe, V.; Hawe, A.; Jiskoot, W. Critical evaluation of nanoparticle tracking analysis (NTA) by NanoSight for the measurement of nanoparticles and protein aggregates. Pharm. Res. 2010, 27, 769-810. [CrossRef] [PubMed]

62. Mehrabi, K.; Nowack, B.; Arroyo Rojas Dasilva, Y.; Mitrano, D.M. Improvements in Nanoparticle Tracking Analysis to Measure Particle Aggregation and Mass Distribution: A Case Study on Engineered Nanomaterial Stability in Incineration Landfill Leachates. Environ. Sci. Technol. 2017, 51, 5611-5621. [CrossRef] 